\title{
Volatile Components of Essential Oil from Cultivated Myrica gale var. tomentosa and Its Antioxidant and Antimicrobial Activities
}

\author{
Mayuko Nakata', Takao Myoda ${ }^{1 *}$, Yoichi Wakita ${ }^{2}$, Takahiro Sato ${ }^{2}$, Ikuko Tanahashi $^{2}$, \\ Kazuki Toeda ${ }^{1}$, Takane Fujimori ${ }^{1}$ and Makoto Nishizawa ${ }^{1}$ \\ ${ }^{1}$ Department of Food and Cosmetic Sciences, Tokyo University of Agriculture, Abashiri 099-2493, Japan \\ ${ }^{2}$ Forestry Research Institute, Local Independent Administrative Agency Hokkaido Research Organization, Bibai city, Hokkaido, Japan
}

\begin{abstract}
Aromatic components in the essential oil prepared from the leaves of cultivated Myrica gale var. tomentosa were compared with those from oil derived wild plants by using gas chromatography-mass spectroscopy (GC/MS). We found that essential oils from both the wild and cultivated plants contained similar aromatic components such as $\beta$-elemenone, selina 3,7(11)-diene, myrcene, limonene, cymene, 1,8-cineole, and $\beta$-pinene, but the content ratio of the oil was significantly different, which might yield differences in the aromatic properties. The aroma impact components of the essential oils were also determined using GC/MS-Olfactometry (GC/MS-O) and aroma extract dilution analysis. Eight aromatic compounds, including linalool, limonene, and 1,8-cineole, were shown to contribute to the aromatic properties of cultivated $M$. gale var. tomentosa. The strongest aromatic note was defined as linalool, followed by limonene, 1,8-cineole, and $\beta$-elemenone. The essential oil, ethanol (EtOH), 1,3-butylene glycol (BG), and 1,3-propanediol (PD) extracts prepared from the leaves of cultivated M. gale var. tomentosa also showed antioxidant and antimicrobial activities, that is, they demonstrated scavenger activity against hydroxyl and superoxide radicals in the aqueous phase, and showed inhibitory effects on lipid peroxidation. The essential oil extracts also exhibited antimicrobial activity against gram-positive bacteria, with the lowest minimum inhibitory concentration value against Bacillus subtilis. In conclusion, the essential oil and solvent extracts from cultivated M. gala var. tomentosa have a potential for utilization as food and cosmetic ingredients.
\end{abstract}

Key words: aroma-impact compund, antioxidant, antimicrobial, essential oil, Myrica gale var. tomentosa

\section{INTRODUCTION}

Myrica gale and other members of the Myricaceae plant family are aromatic shrubs, and are widely distributed in the northern hemisphere. Myrica gale grows about $1 \mathrm{~m}$ high with oblanceolate green leaves, dentate at the top and marked with resinous points. The fruit is a waxy resinous winged drupe. The plant is used in traditional medicine in Northern Europe and North America ${ }^{1)}$. The dried leaves of M. gale are also used as a flavoring agent for beer, and a perfuming agent for linen. Moreover, dried leaves and fruits are used as a spice for soups and stews ${ }^{2}$. However, the commercial applications of $M$. gale have not spread to Northern Europe and America, because of the lack of available resources. In Asia, M. gale var. tomentosa grows in the wild, in the marshes in Japan, especially in Hokkaido, the northern island of Japan. Commercial use of M. gale var. tomentosa in Japan has also not been available.

Recently, we developed a mass propagation system of $M$. gale var. tomentosa by using a shoot tip culture technique. This tissue culture system is ideal for propagating plants with genetic homogeneity.

Using our method, 2 hundred million seedlings can be obtained from one seedling in one year ${ }^{3)}$. Therefore, $M$. gale var. tomentosa is expected to become a new resource owing to its aromatic and medicinal characteristics.

The essential oils of flowers and leaves from M. gale, and other plants of the same family, have been collected in Europe and Northern America, and characterized ${ }^{2,4-8)}$. Anticancer, insect-repelling, and antifungal activities of the essential oils of these plants have been reported ${ }^{6,89}$.

In the present paper, we compared the volatile components in the leaves of cultivated $M$. gale var. tomentosa

\footnotetext{
*Correspondence to: Takao Myoda, Department of Food and Cosmetic Sciences, Tokyo University of Agriculture, Abashiri, 0992493, Japan

E-mail: t1myouda@bioindustry.nodai.ac.jp

Accepted April 5, 2013 (received for review November 22, 2012)

Journal of Oleo Science ISSN 1345-8957 print / ISSN 1347-3352 online

http://www.jstage.jst.go.jp/browse/jos/ http://mc.manusriptcentral.com/jjocs
} 
with those of wild plant by using gas chromatography-mass spectrometry (GC/MS). We also compared the characteristic aromatic compounds (aroma-impact compounds) in the essential oils of cultivated $M$. gale var. tomentosa with wild-type plants by GC-Olfactometry (GC-O). Moreover, antioxidant and antimicrobial activities of essential oil and plant extracts were conducted to investigate their potential for use as natural food additives and/or cosmetic resources.

\section{Materials and methods}

\subsection{Chemicals and solvent}

2,2-Diphenyl-1-picrylhydrazyl were purchased from Sigma-Aldrich (St. Louis, USA). Methanol (MeOH), dimethyl sulfoxide(DMSO), disodium hydrogen phosphate, sodium dihydrogenphosphate anhydrous, tert-butyl hydroxyanisole (BHT), linalool and chloroform were obtained from Kanto Chemical Co(Tokyo, Japan). 1,3-Propanediol was from DuPont Tate \& Lyle Bio Products (Tokyo, Japan), and 1,3-butylene glycol was from Kokyu Alcohol Kogyo Co (Chiba, Japan). SOD assay kit-WST was from Dojindo Laboratories (Kumamoto, Japan) . $\beta$-carotene, polyoxyethylene (20) sorbitan monopalmitate, linoleic acid, cymene, nerolidol, and terpinene-4-ol were from Wako Pure Chemical Industries (Tokyo, Japan). $\alpha$-Pinene, $\beta$-pinene, and limonene were from Tokyo Chemical Industry Co (Tokyo, Japan). 1,8-Cineole and isoamyl isovalerate were from Soda Aromatic Co. (Tokyo, Japan).

\subsection{Plant materials}

Wild M. gale var. tomentosa plants were collected in 2009 in Tomakomai, Hokkaido, Japan. Apical buds (ca. 1.0 $\mathrm{mm}$ ) of the wild plants were immersed in $70 \%$ ethanol for $30 \mathrm{~s}$ and washed with sterilized water. They were further disinfected in $1 \%$ sodium hypochlorite solution containing $0.1 \%$ Tween 20 for $10 \mathrm{~min}$, before being washed 3 times with sterilized water. Shoot tips cut from buds that were approximately $0.5 \mathrm{~cm}$ long were cultured on Woody Plant solid medium ${ }^{10)}$ supplemented with $0.6 \mathrm{mg} / \mathrm{l}$ of 6 -benzylaminopurine at $25^{\circ} \mathrm{C}$ with $16 \mathrm{~h}$ of continuous light for 1 month. The shoots were transplanted into the Woody Plant solid medium supplemented with $0.75 \mathrm{mg} / \mathrm{l}$ of 1-naphthylacetic acid for root initiation. The same culture conditions were used for the shoot-tip culture. The explants obtained via shoot-tip culture were transplanted into pots containing a mixture of vermiculite and pearlite $(1: 1, \mathrm{w} / \mathrm{w})$ and were acclimatized for 3 months in a green house. The plants were then transplanted to fields at the Forestry Research Institute, Hokkaido, Japan, for 3 years $^{3)}$. Leaves collected from these plants represent cultivated $M$. gale var. tomentosa. Leaves collected from wild and cultivated plants were immediately dried in a drying machine at $40^{\circ} \mathrm{C}$ for 3 days.

\subsection{Preparation of essential oil}

Essential oils and aroma water were obtained from dried leaves $(100 \mathrm{~g}$ ) by hydrodistillation with $2,000 \mathrm{ml}$ of distilled water for $1 \mathrm{~h}$.

\subsection{Solvent extraction}

Dried leaves $(100 \mathrm{~g})$ were extracted with $500 \mathrm{ml}$ ethanol (EtOH) , 1,3-butylene glycol(BG) or 1,3-propanediol(PD) $(\mathrm{w} / \mathrm{v})$ at room temperature for 5 days, followed by filtering through filter paper(No. 2, Advantec, Tokyo, Japan). The filtrates were used as the BG and PD extracts, respectively.

\subsection{Gas chromatography-mass spectrometry}

An Agilent 7890A gas chromatograph equipped with a 5975C mass spectrometer was used to analyze volatile compounds. A DB-WAX column $(30 \mathrm{~m} \times 0.25 \mathrm{~mm}$ i.d., 0.25 film thickness; J\&W Scientific) was used for the analysis. The oven temperature was held at $60^{\circ} \mathrm{C}$ for $0.5 \mathrm{~min}$ and then increased to $250^{\circ} \mathrm{C}$ at the rate of $3^{\circ} \mathrm{C} / \mathrm{min}$. The injector and ion source temperature were set at $250^{\circ} \mathrm{C}$ and $230^{\circ} \mathrm{C}$, respectively. Helium was used as the carrier gas at a flow rate of $1.00 \mathrm{ml} / \mathrm{min}$ with a split ratio of $30: 1$ for a $1-\mu \mathrm{l}$ sample injection of oil. Electron impact(EI) spectra were recorded at $70 \mathrm{eV}$, in an $\mathrm{m} / z$ range of $30-400$. The compounds were identified by their GC retention indices that were calculated from the retention time in relation to those of a series of $\mathrm{C}_{8}-\mathrm{C}_{30} n$-alkanes on a 30-m DB-Wax capillary column and by computer matching using AromaOffice 2D (Gestel, Nishikawa). The identification of the compounds was further confirmed by comparison of their fragmentation patterns with those in the literature, and by co-injection with authentic compounds, when possible.

\subsection{Gas chromatography-mass spectrometry/olfactom- etry}

GC/MS-O was performed using an Agilent 7890A-5975C mass spectrometer equipped with an olfactory detection port(ODP2; Gestel). The analytical conditions were the same as those used for the GC/MS analysis.

\subsection{Aroma extract dilution analysis}

The characteristics of aromatic compounds in the essential oil were determined by aroma extraction dilution analysis (AEDA ${ }^{11)}$. Essential oil from dried leaves of cultivated plants was diluted at $30 \%(\mathrm{v} / \mathrm{v})$ with $n$-hexane and subsequently diluted two-fold. The aromatic compounds were separated by GC/MS-O on a DB-WAX capillary column and were sniffed by 3 panelists. The strength of the compounds was expressed by using flavor dilution (FD) factors. FD factors of the characteristic aromatic compounds were determined by the highest dilution factors at which their odors were detectable. 


\section{8 $\mathrm{DPPH}$ radical scavenging assay}

1,1-Diphenyl-2-picrylhydrazyl (DPPH) radical scavenging activity was measured using the spectrophotometric method $^{12)}$ with slight modifications. A freshly prepared solution of $100 \mathrm{mM} \mathrm{DPPH}$ in $\mathrm{MeOH}$ was used. Sample solutions $(100 \mu \mathrm{l})$ at concentrations of $5-400 \mathrm{mg} / \mathrm{ml}$ and $400 \mu \mathrm{l}$ of $100 \mathrm{mM}$ Tris $\mathrm{HCl}$ buffer $(\mathrm{pH} 7.4)$ were mixed with 100 $\mathrm{mM}$ DPPH solution $(500 \mu \mathrm{l})$. The mixture was shaken well and then incubated in the dark for $20 \mathrm{~min}$ at $30^{\circ} \mathrm{C}$ after which the absorbance at $517 \mathrm{~nm}$ was measured.

The anti-oxidative activity of the sample was expressed as inhibition of the DPPH radical quenching calculated using the following equation:

$$
\operatorname{Inhibition}(\%)=\left[\left(\mathrm{A}_{517 \text { (control) }}-\mathrm{A}_{517 \text { (sample) }}\right) / \mathrm{A}_{517 \text { (control) }}\right] \times 100
$$

The $\mathrm{IC}_{50}$ value was calculated from an inhibition curve. The assays were carried out in triplicate. Gallic acid and ascorbic acid were used as positive controls.

\subsection{Superoxide dismutase-like activity assay}

The superoxide dismutase (SOD) -like activity was determined using a SOD Assay Kit-WST(Dojindo Laboratories, Kumamoto, Japan) following the manufacturer's instructions. Briefly, samples were mixed with xanthine oxidase and tetrazolium salt in 96-well microplates for $20 \mathrm{~min}$ at $37^{\circ} \mathrm{C}$. Thereafter, the absorbance was measured at $440 \mathrm{~nm}$ by using a microplate reader. The percentage of inhibition was calculated as follows:

$$
\operatorname{Inhibition}(\%)=\left[\left(\mathrm{A}_{440 \text { (control) }}-\mathrm{A}_{440 \text { (sample) }}\right) / \mathrm{A}_{440 \text { (control) }}\right] \times 100
$$

The $\mathrm{IC}_{50}$ value was calculated from an inhibition curve. Assays were carried out in triplicate, and gallic acid and ascorbic acid were used as positive controls.

\section{$2.10 \beta$-Carotene bleaching assay}

$\beta$-Carotene (10 mg) was dissolved in $10 \mathrm{ml}$ of chloroform. An aliquot $(0.2 \mathrm{ml})$ of this solution was added into a boiling flask containing $20 \mathrm{mg}$ of linoleic acid and $200 \mathrm{mg}$ of Tween 40. Chloroform was removed under reduced pressure at $40^{\circ} \mathrm{C}$ for $5 \mathrm{~min}$, and water $(50 \mathrm{ml})$ was added to the residue with vigorous agitation in order to form an emulsion. The emulsion ( $5 \mathrm{ml}$ ) was added to a tube containing $0.2 \mathrm{ml}$ of the essential oil, aroma water, and extract solutions. Absorbance at $470 \mathrm{~nm}$ was measured immediately after mixing, and the test emulsion was incubated at $50^{\circ} \mathrm{C}$ for $120 \mathrm{~min}$. Absorbance at $470 \mathrm{~nm}$ of the test emulsion was measured every $15 \mathrm{~min}$. BHT was used as the positive control. The antioxidant activities of the samples were evaluated using the following formula:

$$
\operatorname{Inhibition}(\%)=\left(\mathrm{A}_{\mathrm{t}}-\mathrm{C}_{\mathrm{t}}\right) /\left(\mathrm{C}_{0}-\mathrm{C}_{\mathrm{t}}\right) \times 100
$$

where $A_{t}$ and $C_{t}$ are the final $(120 \mathrm{~min}$ )absorbance of the test sample and control, respectively, and $\mathrm{C}_{0}$ is the absorbance for the control.

\subsection{Determination of total phenolic content}

Total phenolic contents were determined using the Folin-Ciocalteau method as described by Singleton et $a l .{ }^{13)}$, using gallic acid as a standard. Sample solutions were prepared by dissolving the sample with $\mathrm{MeOH}$ at a concentration of $1.0 \mathrm{mg} / \mathrm{ml}$. The solutions $(100 \mu \mathrm{l})$ were then mixed with Folin-Ciocalteau reagent $(200 \mu \mathrm{l})$ and incubated for 30 min at room temperature. After addition of $1 \mathrm{~N} \mathrm{NaOH}(500$ $\mu \mathrm{l})$, absorbance at $750 \mathrm{~nm}$ was measured. The total phenolic content was expressed as milligrams of gallic acid equivalents (GAE) per gram of the sample. These assays were also carried out in triplicate.

\subsection{Antimicrobial activity}

\subsubsection{Antimicrobial screening}

Anti-microbial activities against Staphylococcus aureus NRIC 1135, Escherichia coli NRIC 1999, Saccharomyces cerevisiae NRIC 1410, Bacillus subtilis JCM 1465, and Candida albicans JCM 2085 were tested using the paper disc diffusion assay. S. aureus, E. coli and B. subtilus were grown on Nutrient Broth medium and $S$. cerevisiae and $C$. albicans were grown on yeast peptone dextrose (YPD) medium for $24 \mathrm{~h}$ to yield a final concentration of $10^{6}$ $-10^{7} \mathrm{CFU} / \mathrm{ml}$. The microbial suspension $(0.1 \mathrm{ml})$ was spread onto Nutrient Agar (S. aureus, E. coli, and B. subtilus) or YPD Agar(S. cerevisiae and C. albicans) plates, respectively. Sterile filter paper discs (Advantec, $1.6 \mathrm{~mm}$ in diameter) were placed on the surface of the microbial agar plates. The essential oils and solvent extracts $(10 \mathrm{mg} / \mathrm{ml})$ were dissolved in 50\% DMSO and were applied onto the paper discs. Kanamycin $(100 \mu \mathrm{g} / \mathrm{ml}$; Wako Pure Chemical Industries, Japan) and/or aureobasidin A (3.0 $\mu \mathrm{g} / \mathrm{ml}$; Takara Bio Inc., Japan) were used as positive controls against bacterial strains and yeast strain, respectively. The solvent was used as a negative control. The plates were incubated at $25^{\circ} \mathrm{C}$ (C. albicans), $30^{\circ} \mathrm{C}$ (S. cerevisiae and B. subtilus), and $37^{\circ} \mathrm{C}$ (S. aureus and $E$. coli) for 24 h. The diameter (width) of the inhibitory zone was measured after $24 \mathrm{~h}$ of incubation.

2.12.2 Determination of minimum inhibitory concentrations

Micro-well dilution broth susceptibility assays were used to determine the minimum inhibitory concentrations (MICs). Stock solutions of the essential oil were prepared in $50 \%$ DMSO $(100 \mu \mathrm{g} / \mathrm{ml})$ and then serially diluted to make concentrations ranging from 125,000 to $61 \mathrm{ppm}$. Briefly, 96 -well plates were prepared by dispensing $180 \mu \mathrm{l}$ of the diluted inocula into each well. Aliquots of the stock solution of essential oil $(20 \mu \mathrm{l})$ were added to the first series of wells. Each serial dilution $(100 \mu \mathrm{l})$ was then dispensed into 6 consecutive wells. The final volume in each well was 100 $\mu \mathrm{l}$. The contents of each well were mixed on a plate shaker at $300 \mathrm{rpm}$ for $20 \mathrm{~s}$, and then incubated at the appropriate temperature for $24 \mathrm{~h}$. The MIC value was defined as the 
lowest concentration of the essential oil to inhibit the growth of microorganisms.

\section{RESULTS AND DISCUSSION}

3.1 Aromatic composition of wild and cultivated M. gale var. tomentosa

The components of the essential oils prepared from the leaves of wild M. gale var. tomentosa collected in Hokkaido, Japan, are shown in Table 1. According to the area percentage of the peaks in the chromatogram, mono- and sesquiterpenes were major components of the essential oil, and the content of these terpenes was more than $75 \%$. The major compounds found in the oil from wild leaves were $\beta$-elemenone, selina-3,7 (11)-diene, cymene, limonene, 1,8-cineole, and $\beta$-pinene $(13.3 \%, 11.0 \%, 10.6 \%$, $9.8 \%, 7.7 \%$, and $5.0 \%$, respectively). $\gamma$-elemene, $\alpha$-terpinyl

Table 1 Comparisons of chemical composition of the leaf essential oils from wild and cultivated M. gale var. tomentosa.

\begin{tabular}{|c|c|c|c|}
\hline \multirow{2}{*}{ Components } & \multirow{2}{*}{ RI } & \multicolumn{2}{|c|}{ GC peak area (\%) } \\
\hline & & Wild & Cultivated \\
\hline$\alpha$-pinene & 1023 & 1.92 & 3.84 \\
\hline$\beta$-pinene & 1114 & 4.97 & 5.83 \\
\hline$\alpha$-phellandrene & 1169 & 1.25 & 0.12 \\
\hline$\alpha$-terpinene & 1183 & 0.61 & - \\
\hline limonene & 1206 & 9.81 & 10.96 \\
\hline cineole & 1219 & 7.73 & 15.94 \\
\hline$\gamma$-terpinene & 1249 & 0.46 & - \\
\hline cymene & 1276 & 10.6 & 13.12 \\
\hline isoamyl isovalerate & 1299 & 0.42 & 0.57 \\
\hline ylangene & 1490 & 0.22 & - \\
\hline$\alpha$-cubebene & 1499 & 0.22 & - \\
\hline benzaldehyde & 1527 & - & 0.33 \\
\hline linalool & 1549 & 0.97 & 1.45 \\
\hline$\beta$-elemene & 1596 & 0.55 & 0.39 \\
\hline caryophyllene & 1606 & 0.42 & 0.16 \\
\hline terpinen-4-ol & 1610 & 0.80 & 1.56 \\
\hline$\beta$-guaiene & 1614 & 0.59 & - \\
\hline 2,6-dimethyl-1,3,5,7-octatetraene & 1626 & - & 0.18 \\
\hline$\gamma$-elemene & 1644 & 1.85 & 0.85 \\
\hline$\gamma$-muurolene & 1696 & 0.69 & 0.54 \\
\hline$\alpha$-terpinyl acetate & 1703 & 2.68 & - \\
\hline$\beta$-selinene & 1730 & - & 0.95 \\
\hline$\alpha$-selinene & 1734 & 1.21 & 0.60 \\
\hline eremophilene & 1744 & 1.74 & 0.78 \\
\hline lavandulol,acetate & 1761 & - & 1.67 \\
\hline nerol & 1762 & 2.72 & - \\
\hline selina-3,7(11)-dien & 1791 & 11.00 & 3.73 \\
\hline calamenene & 1841 & - & 0.23 \\
\hline benzyl isovalerate & 1898 & 2.16 & 1.17 \\
\hline nerolidol & 2046 & 1.73 & 1.78 \\
\hline$\beta$-elemenone & 2104 & 13.27 & 16.12 \\
\hline 3,7-dimethyl-10-(1-methylethyidene), & 2177 & 1.14 & 1.49 \\
\hline 3,7-cyclodecadien-1-one & & & \\
\hline unidentified & & 20.16 & 14.51 \\
\hline Total & & 99.73 & 99.06 \\
\hline
\end{tabular}

${ }^{a}$ Retention indices (RI) were calculated from retention times in relation to those of a series of C8-C30 n-alkanes on a polar DB-WAX column.

${ }^{\mathrm{b}}$ Not detected. 
acetate, $\alpha$-pinene, nerol, benzyl isovalerate, and nerolidol were also identified. Among the sesquiterpenes, gerumacran and eleman were the most dominant monocyclic sesquiterpenes, whereas caryophyllene, guajan, cadinan, eudesman, and eremophilan were the most dominant type of bicyclic sesquiterpenes. The levels of eleman and eudesman were particularly higher. The components, for which standard samples were available, were quantitatively analyzed by GC/MS, and the results are shown in Table 2. No difference was observed in the contents of the components between wild and cultivated samples.

There have been many reports on the volatile oil composition of sweet gale ( $M$. gale) obtained from different countries $^{2,4-8)}$. The major components of Canadian sweet gale were myrcene, limonene, $\alpha$-phellandrene, and $\beta$ caryophyllene $^{8)} \cdot \alpha$-Pinene and 1,8 -cineole were the major components in the oils collected from Scotland, Finland, and the Netherlands, whereas the contents of myrcene, $\gamma$-terpinene, and $p$-cymene were very low. These results suggest that the composition of volatile components in the essential oil of Japanese M. gale var. tomentosa is different from those in other countries.

It is well known that the composition and the amount of plant volatile compounds varies depending on climatic, geographic, and growing conditions ${ }^{14)}$. Therefore, the essential oil compositions of wild and cultivated plants propagated via shoot tip cultures were compared. The compositions of major compounds of cultivated plants were quite similar to those of wild plants, but the composition ratio of limonene and 1,8-cineole were different(Table 1). In wild M. gale var. tomentosa plants, the limonene content $(9.81 \%)$ was higher than 1,8 -cineole $(7.73 \%)$. In contrast, the contents of cultivated plants was two-fold higher than that of wild plants. In addition, $\beta$-selinene, benzaldehyde, and calamenene were identified only in the essential oil derived from cultivated plants, whereas $\gamma$-terpinene, ylangene, $\alpha$-cubebene, and nerol were not.

Table 2 The contents of the components of essential oil from cultivated M. gale var. tomentosa by GC/MS.

\begin{tabular}{lcc}
\hline \multicolumn{1}{c}{ Components } & Wild $(\mathrm{mg} / \mathrm{g})$ & Cultivated $(\mathrm{mg} / \mathrm{g})$ \\
\hline$\alpha$-pinene & 0.22 & 0.48 \\
$\beta$-pinene & 0.03 & 0.04 \\
limonene & 1.07 & 1.33 \\
cineole & 0.18 & 0.42 \\
cymene & 1.19 & 1.63 \\
isoamyl isovalerate & 0.56 & 0.85 \\
linalool & 0.44 & 0.73 \\
terpinen-4-ol & 1.66 & 3.60 \\
nerolidol & 0.79 & 0.90 \\
\hline
\end{tabular}

These results suggest that the composition of volatile components in cultivated M. gale var. tomentosa is similar to that of wild plants, even though their aromatic properties may differ from each other.

\subsection{Determination of aroma-impact compounds of culti- vated $M$. gale var. tomentosa}

The aroma-impact compounds from the essential oil of cultivated $M$. gale var. tomentosa was then investigated by GC/MS-O analysis and AEDA. Eight aroma-impact compounds were identified from the essential oil(Fig. 1 and Table 3). The strongest aromatic note was given by linalool (FD 128); this was followed by limonene (64), 1,8-cineole (64), and $\beta$-elemenone (64). Among these compounds, $\beta$ elemenone had a unique aromatic note that invoked medicines, which suggests that it plays an important role in the characteristic aroma of cultivated M. gale var. tomentosa.

\subsection{Antioxidant activity of cultivated M. gale var. tomen- tosa}

The antioxidant activities of the essential oil and solvent extracts from the leaves of cultivated M. gale var. tomentosa were evaluated using DPPH assays, SOD like activity assays, and $\beta$-carotene bleaching assays.

The extracts of EtOH, BG, and PD showed DPPH radical scavenging activity, with $\mathrm{IC}_{50}$ values of $134.0 \pm 2.7 \mu \mathrm{g} / \mathrm{ml}$, $17.2 \pm 0.1 \mu \mathrm{l} / \mathrm{ml}$, and $13.5 \pm 0.1 \mu \mathrm{l} / \mathrm{ml}$, respectively (Table 4). SOD-like activities of these extracts showed similar tendency to $\mathrm{DPPH}$ radical scavenging activity. The $\mathrm{IC}_{50}$ values were $171.9 \pm 2.2 \mu \mathrm{g} / \mathrm{ml}, 36.3 \pm 3.8 \mu \mathrm{l} / \mathrm{ml}$, and $22.6 \pm 1.3 \mu \mathrm{l} /$ $\mathrm{ml}$, respectively. These results indicate that the $\mathrm{EtOH}, \mathrm{BG}$, and PD extracts of the leaves of M. gale var. tomentosa can scavenge the hydroxyl and superoxide radicals in the aqueous phase. However, little antioxidant activity was shown in the essential oils.

The $\beta$-carotene bleaching inhibitory activities of the EtOH, BG, and PD extracts are summarized in Table 4. The percentage of $\beta$-carotene bleaching inhibitory activities of the $\mathrm{EtOH}, \mathrm{BG}$, and $\mathrm{PD}$ extracts were $58.1 \% \pm 2.4 \%, 85.8 \%$ $\pm 4.8 \%$, and $72.05 \pm 3.2 \%$, respectively. These results revealed that $\mathrm{EtOH}, \mathrm{BG}$, and $\mathrm{PD}$ extracts from $M$. gale var. tomentosa leaves have not only the hydroxyl and superoxide radicals scavenging activities but also inhibitory effects of lipid peroxidation.

Total phenolic content of the EtOH, BG, and PD extracts were $2.4 \pm 0.1 \mathrm{mg} / \mathrm{g}, 11.8 \pm 0.8 \mu \mathrm{g} / \mathrm{ml}$, and $18.8 \pm 2.6 \mu \mathrm{g} / \mathrm{ml}$, respectively (Table 4). Phenolic compounds are known to have antioxidant effects on plants; therefore, phenolics must be responsible for the antioxidant activity of these extracts.

\subsection{Antimicrobial activity of cultivated M. gale var. tomen- tosa}

The antimicrobial activities of essential oil and solvent 


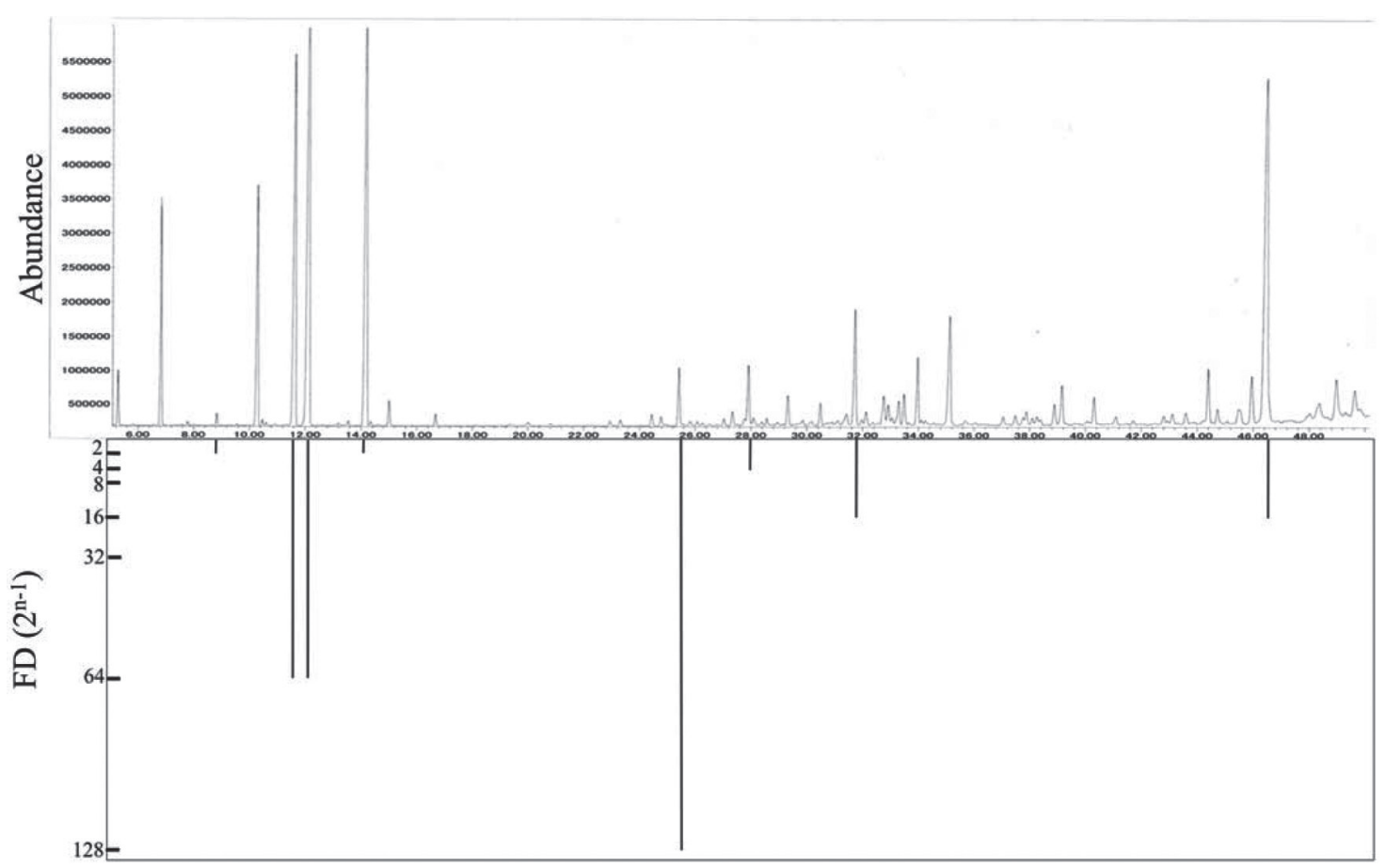

Fig. 1 GC/MS chromatograms (A) and the results of AEDA analysis (B) of the essential oil from cultivated M. gale var. tomentosa leaves.

Table 3 Aroma impact components of the essential oil from cultivated M. gale var. tomentosa.

\begin{tabular}{lclc}
\hline Components & RI & Aroma quality & FD-factor \\
\hline$\beta$-pinene & 1114 & green & 1 \\
limonene & 1206 & citrus & 32 \\
cineole & 1219 & light, woody & 32 \\
cymene & 1276 & citrus & 1 \\
linalool & 1549 & citrus, floral, light & 64 \\
terpinen-4-ol & 1610 & floral & 2 \\
$\beta$-selinene & 1730 & green cut grass & 16 \\
$\beta$-elemenone & 2107 & medicine like & 32 \\
\hline
\end{tabular}

${ }^{a}$ Odor quality perceived at the sniffing port. Flavour dilution factor obtained by AEDA.

extracts prepared from leaves of cultivated M. gale var. tomentosa against Staphylococcus aureus, Escherichia coli, Saccharomyces cerevisiae, Bacillus subtilis, and Candida albicans are shown in Table 5. The essential oil showed antibacterial activity against $S$. aureus, B. subtilis, $S$. cerevisiae, and C. albicans, exhibiting a 3.0-mm inhibition zone in the paper disc assay (data not shown). EtOH, BG, and PD extracts showed no inhibition. The MIC against bacteria exerted by the essential oil was measured using a liquid medium assay. The MIC value against $B$. subtilis was the lowest $(61 \mathrm{ppm})$, whereas other bacteria had values over 1,000 ppm. From these results, we concluded that the essential oil had antibacterial activities against $S$. aureus, B. subtilis, $S$. cerevisiae, and C. albicans, and in particular, strong activity was observed against $B$. subtilis.

There have been many reports on the antimicrobial properties of plant volatile oils and their constituents ${ }^{15,16)}$. Dorman \& Deans ${ }^{17}$ ) summarized the antibacterial activity of volatile components of plants, and a wide activity spectrum was observed by thymol, carvacrol, $\alpha$-terpineol, terpinen4-ol, eugenol, linalool, thujone, $\delta$-3-carene, cis-hex-3-en-1ol, geranyl acetate, citral, nerol, geraniol, menthone, $\beta$ pinene, $\alpha$-terpinene, borneol, sadinene, $\gamma$-terpinene, 1,8 cineole, $\alpha$-phellandrene and cymene. It has been suggested that the antimicrobial activity of cultivated M. gale var. tomentosa is attributed to the complex effects of components of its essential oil such as $\beta$-pinene, 1,8-cineole, linalool, and terpinen-4-ol. The EtOH, BG and PD extracts showed no inhibitory activity against the 4 bacterial strains although these extracts contained monoterpenes such as $\beta$-pinene, $\alpha$-terpineol, terpinen-4-ol, $\gamma$-terpinene, and cymene (data not shown). Further studies are needed to clarify this phenomenon.

\section{CONCLUSION}

The comparison of aromatic components from the leaves of wild and cultivated M. gale var. tomentosa indicated that although there was no significant difference in the components, their content ratio was significantly different. 
Table 4 Antioxidant activities of extracts from leaves of cultivated $M$. gale var. tomentosa.

\begin{tabular}{lcccc}
\hline Extract & $\begin{array}{c}\mathrm{DPPH} \\
\mathrm{IC}_{50}(\mu \mathrm{l} / \mathrm{ml})\end{array}$ & $\begin{array}{c}\mathrm{SOD} \\
\mathrm{IC}_{50}(\mu \mathrm{l} / \mathrm{ml})\end{array}$ & $\begin{array}{c}\text { Inhibition of lipid } \\
\text { peroxidation }(\%)\end{array}$ & $\begin{array}{c}\text { Phenol } \\
(\mu \mathrm{g} / \mathrm{ml})\end{array}$ \\
\hline Oil & $>1000$ & $>1000$ & - & - \\
BG & $17.2 \pm 0.1$ & $36.3 \pm 3.8$ & $85.8 \pm 4.8$ & $11.8 \pm 0.8$ \\
$1,3-\mathrm{PD}$ & $13.5 \pm 0.1$ & $22.6 \pm 1.3$ & $72.0 \pm 3.2$ & $18.8 \pm 2.6$ \\
\hline
\end{tabular}

Data represent the mean \pm S.E. of three separate experiments.

${ }^{a}$ Oil : Essential oil, BG : 1,3-butylen glycol, PD : 1,3-propanediol.

${ }^{\mathrm{b}}$ Not tested.

${ }^{\mathrm{c}}$ Data represent the $\mu \mathrm{g} / \mathrm{ml}$.

${ }^{\mathrm{d}}$ Date represent the $\mathrm{mg} / \mathrm{g}$. .

Table 5 Antimicrobial activities of extracts from leaves of cultivated M. gale var. tomentosa.

\begin{tabular}{lccccc}
\hline \multirow{2}{*}{ Extract } & \multicolumn{5}{c}{ MIC $(\mathrm{ppm})$} \\
\cline { 2 - 6 } & S. aureus & E. coli & B. subtilis & S. cerevisiae & C. albicans \\
\hline Oil & $>1500$ & - & 61 & $>1500$ & $>1500$ \\
$1,3-$ BG & - & - & - & - & - \\
$1,3-\mathrm{PD}$ & - & - & - & - & - \\
Kanamycin & 25 & 50 & 50 & - & - \\
Aureobasidin A & - & - & - & 16 & 16 \\
\hline
\end{tabular}

${ }^{a}$ Oil : Essential oil, BG : 1,3-butylen glycol, PD : 1,3-propanediol.

${ }^{\mathrm{b}}$ MIC : minimal inhibitory concentration, S. aureus : Staphylococcus aureus, E. coli : Escherichia coli, B. subtilis : Bacillus subtilis, S. cerevisiae : Saccharomyces cerevisiae, C. albicans : Candida albicans.

${ }^{\mathrm{c}}$ No inhibition.

${ }^{\mathrm{d}}$ Kanamycin was used for positive control of S. aureus, E. coli and B. subtilis.

${ }^{\mathrm{e}}$ Aureobasidin A was used for S. cerevisiae and C. albicans.

This is the first study to examine the aromatic components in the essential oil of cultivated M. gale plant. The aromaimpact components of the essential oil were also surveyed, and 8 compounds, including linalool, limonene, and 1,8cineole, were shown to contribute to the aromatic properties in cultivated M. gale var. tomentosa. Moreover, the essential oil and extracts of leaves showed scavenging activities against hydroxyl and superoxide radicals as well as inhibitory effects on lipid peroxidation. The essential oil also showed antimicrobial activities against $B$. subtilis.

We have already developed a mass propagation system for $M$. gale var. tomentosa using a tissue culture technique. The results of this study provide further evidence that the essential oil and extracts of leaves from cultivated M. gale var. tomentosa have aromatic and medicinal characteristics and may have a potential use as food or cosmetic ingredients.

\section{ACKNOWLEDGEMENT}

Authors are grateful for financial support from the Japan Science and Technology Agency and LEXIA Inc., Osaka, Japan, and also we acknowledge to Yukina Sekine and Yoshitaro Saito for supportingl of this study.

\section{References}

1) Malterub, K. E. \& Faergi, A. Bacteriostatic and fungistatic activity of C-methylated dihydrochalcones from the fruits of Myrica gale L. A Pharm. Suec. 19, 43-46 (1982).

2) Svoboba, K. P., Inglis, A., Hampson, J., Galambosi, B., and Asakawa, Y. Biomass production, essential oil yield and composition of Myrica gale L. harvested from wild populations in Scotland and Finland. Flavour Fragr. J. 13, 367-372 (1998).

3) Wakita, Y., Sato T., Tanahashi, I., Ishii, H. and Sato, T. Developmenet of the micropropagation technology 
and inspection of the relaxation effect in the Myrica gale var. tomentosa. Bor. For. Res. 60, 85-87 (2010).

4) Carlton, R. R., Waterman, P. G., Gray, A. I., and Deans, S. G. Variation of leaf gland volatile oil within a population of sweet gale (Myrica gale) (Myricaceae). Chemoecology. 3, 45-54 (1992).

5) Halim, A. F. and Collins, R. P. Essential oil analysis of the Myricaceae of the Eastern United State. Phytochemistry. 12, 1077-1083(1973).

6) Jeanson, T. G. T., Palsson, K. and Borg-Karlson, A. K. Evaluation of extracts and oils of tick-repellent plants from Sweden. Medical and Veterinary Entomology. 19, 345-352 (2005).

7) Lawrence, B. M. and Weaver, K. M. Essential oil and their constituents. Planta Medica. 25, 385-388 (1974).

8) Sylvestre, M., Legault, J., Dufour, D. and Pichette, A. Chemical composition and anticancer activity of leaf essential oil of Myrica gala L. Phytomedicine. 12, 299-304 (2005).

9) Popvici, J., Bertrand, C., Bagnarol, E., Fernandez, M. P. and Comte, G. Chemical composition of essential oil and headspace-solid microextracts from fruits of Myrica gale L. and antifungal activity. Natural Product Research. 22, 1024-1032 (2008).

10) Lloyd, G. \& McCown, B. Commercially feasible micropropagation of mountain laural (Kalmia latifolia) by use of shoot tip cultures. Ccmb Proc. Intl. Soc. 30,
421-427(1980).

11) W. Grosch. Detection of potent odorants in foods by aroma extract dilution analysis Trends Food Sci. Technol. 4, 68-73(1993).

12) Bolis, M. S. Antioxidants determination by the use of a stable free radical. Nature. 4617, 1199-1200 (1958).

13) Shingleton, V. L., Orthofer, R. and Lamuela-Raventós, R. S. Analysis of total phenols and other oxidation substrates and antioxidants by means of Folin Ciocalteau Reagent. Method Enzymol. 299, 152-178(1999).

14) Baydar, H., Sagdic, O., Ozkan, G., and Karadogan, T. Antimicrobial activity and composition of essential oils from Origanum, Thymbra and Satureja species with commercial importance in Turkey. Food Control. 15, 169-172 (2004).

15) Mangena, T. \& Muyima, N. Y. O. Comparative evaluation of the antimicrobial activities of essential oils of Artemisa afra, Pteronia incana and Rosmarinus officinalis on selected bacteria and yeast strains. Letters in Applied Microbiol. 28, 291-296 (1999).

16) Kivrak, I., Duru, M. E., Öztürk, M., Mercan, N., Harmsndar, M. and Topçu, G. Antioxidant, anticholinesterase and antimicrobial constituents from the essential oil and ethanol extract of Salvia potentillifolia. Food Chem. 116, 470-479 (2009).

17) Dorman, H. J. D. and Deans, S. G. 2000. Antimicrobial agents from plants: antibacterial activity of plant volatile oils. J. Applied Microbiol. 88, 308-316 (2000). 